\title{
El año cervantino en Serbia
}

\author{
JASNA STOJANOVIĆ*
}

Últimamente más conocida por sus armas que por sus letras, Serbia, sin embargo, afirma su identidad artística y europea en autores como Dositej Obradović, el fundador de la moderna literatura serbia, que - el primero entre nosotros - lee Don Quijote y lo recomienda a sus compatriotas. Desde entonces, la obra cervantina se aprecia, traduce e imita, lo que, no obstante, se reconoce y valora plenamente solo ahora (nuestro cervantismo es una disciplina joven). Las últimas investigaciones confirman que la huella de Cervantes, sobre todo en la génesis de la novela en este suelo, es indeleble, como lo es también en la formación de los más grandes prosistas que dio este país: Ivo Andrić, Premio Nobel y autor de Un puente sobre el Drina, Miloš Crnjanski, escritor de Migraciones, o Danilo Kiš, por mencionar solo los más conocidos en Occidente.

Pero las letras no son el único campo donde florecen plantas de raíz cervantina. En Serbia también don Quijote y Sancho están en todas partes: en la pintura, en el teatro, en la música, en el cine, en la lengua, en la calle. Son un mito cultural perfectamente adaptado, lo que, sin lugar a dudas, viene demostrado por la atención prestada a novela y autor a lo largo de 2005. Hemos observado y analizado este fenómeno en el siguiente trabajo, realizado en la Cátedra de Estudios Ibéricos de la Facultad de Filología de Belgrado por los estudiantes Hristina Vasić, Jelena Jovanović, Darko Stojković y su profesora, JASNA STOJANOVIĆ.

* Universidad de Belgrado. 
La obra del genio alcanza más lejos que él mismo, superando las tendencias y las fronteras ${ }^{1}$.

Es indiscutible la importancia e influencia que, después de cuatro siglos, tiene Don Quijote en la cultura mundial, especialmente en la literaria. Como en tantos países, en Serbia el año 2005 ha transcurrido bajo el signo de Miguel de Cervantes y su magna obra, con numerosos eventos para celebrar los cuatrocientos años de la publicación de la primera parte de la novela.

\title{
NuEVAS TRADUCCIONES
}

\begin{abstract}
... importa mucho más hacer traducir e imprimir en nuestra lengua, cueste lo que cueste, un libro inteligente y útil, que construir doce campanarios y colocar en ellos grandes campanas; nuestros hijos no serán por ello más inteligentes, incluso si las campanas doblaran hasta el final de su vida (Dositej Obradović, Consejos de razón sana, 1784)².
\end{abstract}

La nueva traducción serbia de Don Quijote es, sin lugar a dudas, una de las aportaciones más notables del centenario en nuestro país. Su autora, la hispanista Aleksandra Mančić, declaró en una entrevista para el diario Politika que la traducción de una obra no es eterna y que había llegado el momento de elaborar una nueva versión. Según las palabras del redactor de la casa editorial Rad, Jovica Aćin, la nueva traducción es «por fin, moderna de verdad» y «representa la cumbre en el arte de traducir, habiendo conseguido transformar lo antiguo en lo eternamente nuevo, en una versión caballeresca de verdad» ${ }^{3}$. La elaboración de este Quijote ha durado dos años. Aleksandra Mančić ha tenido varios encuentros con el público belgradense, en un intento de explicar la dificultad y seriedad de la hazaña. Asimismo, ha hablado de sus dudas en el simposio organizado por el PEN centroamericano en Nueva York, en abril de 2005. Hay que subrayar que Mančić es la primera hispanista que vierte Don Quijote al serbio, y que la traducción se ha realizado gracias al apoyo de la Dirección del Libro, Archivos y Bibliotecas del Ministerio de Cultura de España. En cuanto a la valoración de esta versión, su comparación con el original y las traducciones existentes (la de Djordje [Jorge] Popović, de 1895-1896, y la de

1. Vinko VitezicA, «El ingenioso hidalgo Don Quijote de la Mancha», Misao, VI/104, 1924, pp. $620-625$.

2. «Bolje je mnogo jednu pametnu i poleznu knjigu, s kolikim mu drago troškom, dati da se na naš jezik prevede i naštampa, nego dvanaest zvonara sazidati i u sve nji velika zvona poizvešati; zrno pameti neće se deci našoj pridodati, ako će im doveka zvona lupati» (Apud Jasna Stojanović, Servantes $u$ srpskoj književnosti, Beograd, ZUNS, 2005, p. 18).

3. «Konačno istinski savremen, vrhunski u umetnosti prevođenja i, pretvarajući staro u svevremeno novo, pravi viteški prevod» (Migel de Servantes, Don Kihote od Manče, Beograd, Rad, 2005, vol. 2 [portada]). 
Duško Vrtunski, de 1988), es, desde luego, una tarea que espera a los especialistas.

«Cuando uno se propone traducir un libro como este, le pasan cosas dignas de escribirse en un diario» ${ }^{4}$, explica Aleksandra Mančić el porqué de su libro Los molinos a lengua, publicado a raíz de la salida del nuevo Quijote serbio. Su texto, además de mencionar los eternos dilemas del traductor y las búsquedas quijotescas de palabras o expresiones, viene salpicado por datos sobre la España barroca, así como sobre la vida de Cervantes. Fue presentado en la Feria del Libro de Belgrado en octubre de 2005.

Mencionemos brevemente que durante la celebración aparecieron en las librerías de Belgrado, traducidos por Jelena Plavšić, dos títulos de Andrés Trapiello, Al morir don Quijote y Las vidas de Miguel de Cervantes. También se tradujo La ruta de Don Quijote de Azorín, escrito con motivo del tercer centenario (1905), libro en que este representante de la Generación del 98 revela a los lectores la esencia del espíritu español desde la perspectiva de un narrador melancólico y resignado. La traductora ha sido Biljana Bukvić y la editorial Utopija de Belgrado.

\section{ESTUDIOS CRÍTICOS}

El libro Cervantes en la literatura serbia, de Jasna Stojanović, profesora de Literatura Española en la Universidad de Belgrado, ofrece una visión integral de la difusión e influencia de la obra cervantina en nuestras letras desde 1784 (la primera mención del Quijote) hasta la actualidad. El volumen contiene los capítulos «Don Quijote y la literatura serbia: influencias y analogías», «La primera traducción de Don Quijote de Djordje Popović - Daničar» y «Miguel de Cervantes y su obra en la crítica literaria serbia». Incluye una bibliografía de traducciones serbias de las obras cervantinas, en la que se dan conjuntamente los títulos publicados en forma de libro y de revistas. Contiene también una bibliografía de textos críticos publicados entre 1838 y 1999. Igualmente, el lector interesado en el tema puede encontrar un análisis detallado de las obras de prosistas serbios influidos por el novelista español, como por ejemplo Jovan Sterija Popović, Jakov Ignjatović, Stevan Sremac y Laza Lazarević del siglo XIX y Radoje Domanović, de principios del XX (entre otros). Según la autora, los elementos narrativos cervantinos más imitados han sido: el personaje del caballero manchego, la pareja don Quijote-Sancho, el tema del conflicto con la realidad, la crítica de la herencia literaria, los motivos típicos, así como algunos aspectos de la técnica novelesca 5 .

4. «Ima mnogo stvari koje vam se dešavaju kad uzmete da prevodite jednu ovakvu knjigu, pa to zaista zaslužuje dnevnik» (AlEKSANDRA MANČIĆ, «Don Kihote među Srbima», Politika, 2.VIII.2005).

5. En el diario belgradense Politika se publicaron fragmentos del libro en nueve entregas, del 28 de abril al 8 de mayo de 2005. Gracias a la gran difusión del periódico en el país y en el territorio ex yugoslavo, el texto alcanzó un gran número de lectores. 
En la reseña del libro, el académico Zoran Konstantinović valoró positivamente el esfuerzo realizado por la autora, invitando a los lectores a buscar las vías del desarrollo espiritual serbio precisamente en estudios monográficos como este, puntualizando que nuestra cultura echaba de menos un trabajo tan completo sobre el escritor español, a pesar de la larga presencia de Don Quijote en ella («El serbio como un don Quijote») ${ }^{6}$.

\section{ARTÍCULOS EN LA PRENSA}

Durante 2005, numerosas revistas literarias, semanarios y diarios dedicaron varios artículos a la novela cervantina, contribuyendo a su mayor difusión, aunque, hay que decirlo, desde perspectivas muy variadas. Destacamos los más representativos.

En diciembre de 2005, la revista literaria Letopis Matice srpske de Novi Sad (la más antigua de Serbia, cuyo primer número se remonta a 1825), publicó el artículo «Don Quijote de Cervantes hoy: estudio y valoración», en el cual Ljiljana Pavlović-Samurović, la recién fallecida catedrática de la Facultad de Filología de Belgrado, presentó un resumen de los actos conmemorativos en España y en el mundo, enfocando en primer lugar a la crítica, tanto científica como esotérica. Luego pasó revista a las ediciones de la novela, mencionando la de Francisco Rico como la mejor realizada hasta la fecha, para referirse luego a las recientes biografías de Cervantes (de Jean Canavaggio, Alfredo Alvar Ezquerra y Andrés Trapiello), desde luego muy diferentes entre sí.

«Don Quijote y las novelas sociales de Jakov Ignjatović» es el título del estudio de Jasna Stojanović sobre la influencia de Cervantes en este gran novelista serbio del siglo XIX, notable sobre todo en los protagonistas de sus obras El novio eterno (1878), Milan Narandžić (1860-1862) y Vasa Rě̌pekt (1875). Comparando el estilo y la técnica narrativa de los dos escritores, su vocabulario y otros rasgos más, salta a la vista, según dice la autora, que Ignjatović bebió en la fuente de Cervantes.

«Cervantes en Helgoland» es otro trabajo de J. Stojanović en el que se analiza la huella de Don Quijote en las obras del prosista contemporáneo Radomir Smiljanić. En tres novelas, publicadas a lo largo de los años setenta del siglo pasado, aparece Hegel, una especie de don Quijote socialista, aunque es posible rastrear muchas similitudes más: en los temas y motivos, en la organización de la fábula, hasta en la técnica narrativa, que, según subraya Jasna Stojanović, indica por lo menos dos cosas: «primero, la importancia de la obra cervantina en el bagaje humano y artístico del escritor serbio y, luego, su vitalidad, es decir, su calidad de pilar principal en la construcción de la trilogía de Smiljanić»»7

6. Zoran KonstantinOvić, «Srbin kao Don Kihot», NIN, 2868, 2005, pp. 52-53.

7. «Snagu kojom je Servantesovo ostvarenje utemeljeno u ljudski i spisateljski prtljag srpskog pisca, a zatim njegovu vitalnost, to jest sposobnost da bude jedan od nosećih stubova u gradjevini 
En el periódico Philologia salió el artículo «Las Novelas ejemplares en la versión de Hajim Alkalaj», donde J. Stojanović sintetiza los resultados de su análisis de la traducción de las novelas El celoso extremeño, La ilustre fregona y El licenciado Vidriera, realizada por el sefardí Hajim Alkalaj en 1938. La autora estima que esta traducción llenó en su tiempo un gran vacío en el conocimiento de Cervantes, resaltando que «la versión de Alkalaj consigue trasponer las ideas del autor y el espíritu del original; se lee bien y fluye naturalmente, aunque [...] su estilo es un poco anticuado. Sin embargo, a pesar [...] de cierto número de serios errores materiales, subrayamos que Alkalaj reveló al lector serbio la temática, el estilo y las ideas del primer novelista español, que no es un pequeño mérito» ${ }^{8}$.

El número monográfico de la revista Krajina de Banja Luka (ciudad de la República Serbia, una de las dos entidades de la Federación de Bosnia-Herzegovina), titulado Don Quijote 1605-2005, trajo en agosto de 2005 una serie de textos originales y traducidos sobre la novela de Cervantes. De hecho, es una antología de opiniones representativas, publicadas entre 1929 y 1989, de destacados críticos serbios pertenecientes a varias generaciones: Isidora Sekulić, Sreten Marić, Nikola Milošević, Svetozar Koljević, Ljiljana Pavlović-Samurović y Mladen Šukalo, pero también de escritores extranjeros, por lo general ya conocidos del público serbio (de Borges o de Kafka, véase la bibliografía), así como algunas aportaciones nuevas, como las de Margit Frenk, Mario Vargas Llosa o Carlos Fuentes.

En diciembre de 2005 Branislava Jevtović escribió en Književne novine (Periódico literario) sobre «Cuatro siglos de don Quijote, del rey Lear y de Otelo», obras que ve como «narraciones-tipo sobre espíritus cautivos, caracteres liberales y la imposibilidad del hombre de adquirir conocimientos nuevos» ${ }^{9}$. El loco, Sancho y Yago vienen representados como «un trío de manipuladores» que juegan a propósito contra la razón sana y la confianza de sus superiores, o sea el rey Lear, Otelo y don Quijote. La autora destaca que el objetivo de la novela de Cervantes es la cristianización del héroe pagano épico y dice que su conversión interior, el acto de fe y el hecho de que lleva su propia cruz hacen de don Quijote un personaje estéticamente atractivo.

La revista Hereticus publicó el artículo de Obrad Stanojević, profesor de la Facultad de Derecho de Belgrado, cuyo título «Don Quijote y las ortigas de Paraćin» lleva al lector a la tesis (como dice el autor, «herética») de que el libro de Cervantes es una obra burlesca que se mofa descaradamente del protagonista. Según esta interpretación, la novela sería el resultado de la dura vida

Smiljanićeve trilogije» (M. Šukalo, J. Stojanović [coords.], Don Kihot 1605-2005, Krajina, 15, 2005, p. 219).

8. «Alkalajeva verzija uglavnom uspeva da dočara piščeve ideje i duh originala; lepo se čita i teče dosta prirodno, mada [...] pomalo zastarelo. Iako se [...] ukazuje izvestan broj ozbiljnih slabosti, podvlačimo da je Alkalaj srpskom čitaocu otkrio tematiku, stil i ideje prvog španskog noveliste, što nije mala zasluga» (Philologia, 3, 2005, p. 225).

9. «Tipsku priču o zarobljenim umovima, slobodarskim prirodama i nemoći čovekovoj da saznaje» (B. JevTović, «Četiri veka Don Kihota, kralja Lira i Otela», Književne novine, 1124, 2005, p. 6). 
del escritor, producto de unos tiempos crueles y de la mentalidad agresiva típica de las ciudades pequeñas. En efecto, nos dice el profesor Stanojević, en época de Cervantes Madrid no tenía más de veinte o treinta mil habitantes, igual que hoy Paraćin, una población serbia donde, hace unos años, un grupo de jóvenes delincuentes maltrató con ortigas a un muchacho indefenso. Aduciendo detalles interesantes sobre Europa y España en el siglo XVII y constantes referencias a la actualidad, el autor resalta su discrepancia con la imagen tradicional del hidalgo que provoca lástima.

El 24 de abril de 2005 aparece en la revista Vreme (Tiempo) el artículo del escritor Vladimir Tasić «Sobre la inmortalidad: Don Quijote en la literatura mundial». Tasić habla de Don Quijote como inspiración de muchos artistas, escritores y músicos internacionales conocidos (pero también desconocidos), participando de su herencia literaria en territorio serbio la novela perdida de Miloš Crnjanski El hijo de Don Quijote y los diarios de Borislav Pekić, con apuntes para el cuento Don Quijote de la Mačva (o sea, Machva, una región serbia). Lo más interesante del artículo radica en la lista de fracasos editoriales, como, por ejemplo, Don Quijote moderno o El marido estúpido de mi mujer de August Berkley, de 1884, Don Coyote de Whitman Chambers de 1927 (el caballero como cow-boy), o el cuento de ciencia-ficción de Paul Anderson El Quijote y los molinos de viento, donde el hidalgo es un robot triste sin tarea precisa, condenado a errar eternamente en un mundo especializado.

El autor del artículo «Nuestro primo de la Mancha», Vladimir Pištalo, intenta responder al dilema de Borges, es decir, «¿Qué hubiera pasado con don Quijote si en un momento de locura hubiera matado a alguien de verdad?». Borges ofrece dos posibilidades; en la primera, el asesinato acaba con sus obsesiones caballerescas, y en la segunda, el hidalgo sigue cabalgando en su locura de heroísmo y nobleza. Más incómoda aún sería la pregunta: ¿qué hubiera pasado si don Quijote hubiera aparecido cien años antes, y si Hernán Cortés le hubiera llevado consigo a México? La respuesta depende de si «la locura de don Quijote hubiese escogido ver a los indios como a gente desprotegida, o hubiese escogido verles como demonios. En el segundo caso, el hidalgo conmovedor podría convertirse no solo en un asesino, sino en un asesino masivo» ${ }^{10}$.

Para el psicólogo Žarko Trebješanin don Quijote es el «tipo universal del soñador, del luchador contra la injusticia, un poco loco y anacrónico», y el «donquijotismo» una actitud caballeresca exagerada, que sobreentiende una tendencia hacia la fantasía y la mitomanía. Trebješanin ve a los serbios como una nación que presenta rasgos de este tipo de comportamiento. El reformador de la lengua y compilador de la literatura oral serbia, Vuk Karadžić, lo notó hace mucho tiempo (en el siglo XIX), diciendo que nuestro pueblo «sigue vi-

10. «... šta bi se desilo da je Kihot u svom ludilu ubio čoveka? [...] Sve zavisi od toga da li bi Kihotovo ludilo odabralo da Indiose vidi kao neodbranjene ljude koje bi trebalo zaštititi, ili kao demone. U ovom drugom slučaju dirljivi vitez mogao bi postati ne samo ubica nego masovni ubica» (V. PIšTALO, «Svačiji rođak iz Manče», Vreme, 739, 3.III, 2005). 
viendo en aquel mítico siglo de oro». Según Trebješanin, este rasgo, junto con la percepción de mitos y canciones épicas como realidad, es una característica general del pueblo serbio. Después de numerosos fracasos políticos y militares en la última década, los serbios han recorrido un largo camino, y de una Serbia celestial han llegado a «una Serbia sucia y terrestre, y aún más, a una Serbia subterránea, oscura». Trebješanin opina que don Quijote es imprescindible para los serbios «para recordarnos que un hombre sin sueños, sin ideales y sin ilusiones, y sin una miga de locura, estaría condenado a una realidad baja, pobre y fea, que no es otra cosa que el reino de la maldad y la injusticia» ${ }^{11}$.

\section{CONFERENCIAS}

Durante 2005 un número considerable de especialistas en varios campos de la ciencia y de la cultura presentó a los belgradenses sus investigaciones sobre la obra cuya fama no ha disminuido en cuatrocientos años.

En la manifestación cultural «Días de Don Quijote», celebrada en el Instituto Cervantes de la capital serbia (19 a 28 de abril de 2005), se pronunciaron varias conferencias sobre la presencia de Don Quijote en nuestra literatura, tanto antigua como moderna, la pintura, la música y la filosofía. De hecho, en 2006 salieron las actas de este coloquio interdisciplinario, en serbio y español, tituladas Don Quijote en la cultura serbia ${ }^{12}$.

El 17 de septiembre se organizó el «Mediodía literario» en honor a Cervantes en un céntrico parque de Belgrado, Tašmajdan, donde, enfrente de un restaurante muy popular, se encuentra la escultura de don Quijote. Jasna Stojanović habló sobre el Caballero de la Triste Figura; el historiador de arte Uglješa Rajčević explicó la obra de Jovan Soldatović, autor de la escultura «Don Quijote», y la traductora Aleksandra Mančić presentó su versión de Don Quijote. Los actores Aleksandar Dunjić y Milenko Pavlov leyeron un diálogo entre el señor y su criado, y Ratomir Rale Damjanović leyó un fragmento de su novela La versión de Sancho, cuya historia transcurre justamente en el lugar de celebración de este evento ${ }^{13}$.

11. «... da nas podseti da bi čovek bez snova, ideala, zanesenjaštva i makar zrnca ludila, bio osudjen na ružan, prizeman i ubog život u realnosti, koja je drugo ime za carstvo zla i nepravde» (ŽARKO TREBJEŠANIN, «Donkihotizam u Srba» [«El donquijotismo entre los serbios»], Glas javnosti [Voz pública], 30, 2005, IV.

12. Contiene los trabajos siguientes: Dragan Aleksić, «Don Quijote del Bramante. Radio drama infantil», Nikola ŠUicA, «Los tipos de representación de Don Quijote en las pinturas de Radomir Reljić», Vladimir Jovanović, «Triunfo de la Ópera de Belgrado en los teatros europeos con Don Quijote de Massenet (1957-1969)», IVA DrAŠKIĆ VIĆANOviĆ, «Don Quijote: mito filosófico internacional y supranacional» y JASNA STOJANOVIĆ, «Don Quijote en Serbia: recepción de un personaje». El renombrado comparatista ZoRAn KonstantinOvić publicó la reseña de esta edición («Don Kihot i Verter», Politika /Kultura, umetnost, nauka/, 14, julio 2006, p. 10).

13. El poeta RAdosLaV VoJVODić es autor de un poema sobre la escultura de Don Quijote en Tašmajdan, publicado en la revista Stig (24, 2005, pp. 22-23). 
En noviembre de 2005 en la sede de la comunidad judía de Belgrado la profesora Jasna Stojanović pronunció una conferencia sobre los sefardíes serbios/yugoslavos y Cervantes. Habló de la labor de Hajim Davičo, autor de la primera traducción de dos entremeses cervantinos (1905), de Hajim Alkalaj, traductor de tres novelas ejemplares (1938) y de Kalmi Baruh, primer hispanista yugoslavo y doctor en filología románica, que murió en un campo de concentración nazi. La actividad de estos sefardíes, en una época en que Serbia y Yugoslavia no tenían especialistas en temas españoles, representa una valiosa contribución a la fundación de los estudios hispánicos y cervantinos en nuestra región.

\section{EXPOSICIONES}

Hace mucho que Don Quijote apareció en la historia del arte y desde entonces no dejó de inspirar a grandes pintores, escultores y diseñadores. Según explica el grabador serbio Nenad Nikolić, «cualquier artista sincero es un poco don Quijote: soñador, fantástico e idealista; un ser al que nadie entiende, del que todos se ríen, y que siempre es optimista y nunca desespera, porque - como dijo Cervantes - la desesperación es el mayor pecado». A lo largo de $2005 \mathrm{se}$ organizó en Serbia un gran número de exhibiciones en torno a Don Quijote: el 20 de septiembre, en la galería del Instituto Cervantes, Nenad Nikolić presentó sus grabados y dibujos inspirados por el caballero andante. Tras haber viajado por Serbia, estos trabajos se exhibieron en varias galerías y bibliotecas de la capital. El artista explicó el carácter móvil de la muestra diciendo que le gustaría presentar su obra incluso en bibliotecas de pueblo, en tabernas y escuelas rurales, y dar a los niños una clase sobre cómo atacar los molinos de viento. Después del Instituto, la exhibición se trasladó a la biblioteca pública Isidora Sekulić, y el 23 de febrero de 2006 Nikolić presentó una exposición sobre don Quijote y el héroe nacional serbio Marko Kraljević en la Biblioteca de la ciudad de Pančevo, donde se expusieron también varias ediciones de libros que tratan de estos dos personajes míticos.

La sala de exposiciones del Instituto Cervantes hospedó tres muestras más: en abril, una exposición de carteles sobre tema quijotesco, realizados por los estudiantes de diseño gráfico de la Facultad de Artes Aplicadas de Belgrado y Kragujevac, y bajo la dirección del profesor Zdravko Mićanović; en junio, una muestra de trajes de los personajes de Don Quijote de la Mancha, diseñados y realizados por los estudiantes de la profesora Dijana Mihajlović de la Academia de Bellas Artes de Belgrado, oportunidad única de presentar estas creaciones estudiantiles en público; finalmente, una exposición de carteles de películas sobre Don Quijote, ideada por Enrique Camacho, donde se pudieron ver cuarenta carteles en diferentes lenguas europeas. 


\section{TEATRO}

Justo al finalizar el año conmemorativo, el 28 de diciembre, se estrenó Don Quijote según el texto de Mijaíl Bulgákov y bajo la dirección de Dragan Jovanović, que interpretó también el papel principal. Este era su primer trabajo como director y su deseo era realizar el proyecto en Zemun, su ciudad natal, así que la pieza se puso en escena en el teatro Madlenianum. Sancho Panza fue interpretado por el conocido actor Petar Kralj, que desempeña al mismo tiempo otros papeles más; los demás actores son Nebojša Ljubišić, Branka Pujić, Rade Marković Mlađi, Nada Macanković, Petar Benčina e Igor Benčina. La representación todavía sigue en cartel, y el director declaró que los personajes van creciendo y perfilándose cada vez mejor de interpretación en interpretación.

Con motivo del cuarto centenario, Radio-televisión Serbia, en su programa Trezor (Tesoro), volvió brevemente al pasado emitiendo la pieza teatral Don Quijote y Sancho Panza en el Teatro Contemporáneo de Belgrado (escena de Crveni krst), estrenada en el año 1972. La grabación se emitió los días 5 y 6 de septiembre. La función se basó en la dramatización de Mijaíl Bulgákov, con los famosos actores serbios Predrag Ejdus y Marko Nikolić interpretando los papeles principales.

El Teatro Sunce (Sol) de Kraljevo contribuyó al año cervantino con una representación experimental, titulada Don Quijote. El grupo participó en el XIII Festival de Nuevas Formas Teatrales de Smederevska Palanka, donde ganó el segundo premio y el premio especial para la mejor puesta en escena, mientras que la actriz Jasmina Radović ganó el premio para el mejor papel secundario femenino. Se trata de teatro alternativo, de un intento exitoso de trasladar la historia del Quijote a nuestra tierra en forma de teatro tragicómico de movimento. El autor del proyecto fue Zoran Savković Džeri, y los compositores Aleksandar Kneževica y Dubravka Mališić. La representación se estrenó también en Belgrado, Šabac y Gornji Milanovac.

Alonso Quijano el Bueno, pieza teatral para niños, se representó en el teatro belgradense Boško Buha en el marco del festival de teatro infantil FESTIC. Fue una función a cargo de la Compañía española DATEDANZA de Granada.

En honor de Cervantes también actuaron, bailaron y cantaron los estudiantes de lengua y literatura españolas de la Facultad de Filología de Belgrado, cuyo grupo teatral «Los Cosmos» representó el 25 de marzo el entremés $E l$ juez de los divorcios, bajo la dirección de Jasmina Nikolić y Salomé Monasterio. Esta breve pieza se puso en escena primero en una de las salas más importantes de la facultad («Sala heroja»), con participación de actores, músicos y bailarines, y luego, unos días más tarde, en la calle peatonal de Belgrado, Knez Mihajlova, enfrente del Instituto Cervantes, esta vez en serbio. 


\section{BALLET Y ÓPERA}

Durante 2005 en el Teatro Nacional de nuestra capital se representó el ballet Don Quijote de Ludwig Minkus, estrenado en 1988, en cuyo elenco participaron nombres famosos del ballet nacional (Konstantin Kostjukov, Mila Dragićević, Ana Pavlović, Denis Kasatkin), Angel Šurev como director de orquesta, Vladimir Logunov como coreógrafo, el escenógrafo Boris Maksimović y la diseñadora de vestuario Božana Jovanović.

Desde el 14 de octubre de 2003 en el Teatro Nacional se representa también la ópera Don Quijote de Jules Massenet, bajo la dirección de Samur Ranković. La adaptación de música para el cuarteto de violines es de Angel Šurev, también director de orquesta.

A la conmemoración se sumó el Ballet Nacional Húngaro de Budapest con una actuación extraordinaria, el 1 de octubre, en el Centro de Congresos de Belgrado Sava. El papel principal femenino fue confiado a la bailarina Alesya Popova, y su pareja fue Jozef Certa.

\section{CINE}

Rocinante! No, you can't eat! To get those ribs you don't have make-up. The pelvic bones are fantastic. Look at them! $!^{14}$.

La Biblioteca Nacional de Serbia, en colaboración con el Instituto Cervantes, organizó del 6 al 12 junio el ciclo de películas «Don Quijote a través de la historia del cine». Los visitantes pudieron ver siete películas ${ }^{15}$, y como suplemento se proyectaron siete cortometrajes ${ }^{16}$.

Vale la pena mencionar también dos ediciones DVD: la empresa Neo-film de Belgrado sacó la película El caballero Don Quijote de Manuel Gutiérrez Aragón, mientras que la segunda, de la casa City Records, es de dibujos animados y lleva por título Luchando contra los molinos (U borbi protiv vetrenjača).

14. «¡Rocinante! ¡No comas! No tienes maquillaje para estas costillas. Los huesos pélvicos son fantásticos. ¡Míralos!» (Terry Guilliam, de la película Lost in la Mancha, España, 2001).

15. De George Wilhelm Pabst, 1933; Grigori Kozintsev, 1957; Rafael Gil, 1947; Roberto Gavaldón, 1972; Orson Welles y Jesús Franco, 1955/1992; Peter Yates, 2000 y Manuel Gutiérrez Aragón, 2002 .

16. De Amaro Carretero, 1976; Vlado Kristl, 1961; Cruz Delgado, 1979; Ramón Masats, La Mancha de Cervantes, 1968; Stoyan Dukov, El caso Don Quijote, 1968; Vadim Kurchevskiy, Don Quijote liberado, 1987; Manuel Gutiérrez Aragón, 1991. 


\section{CONCIERTOS}

«En el campo musical, Don Quijote ha superado todas las barreras culturales y estilísicas» ${ }^{17}$. De hecho, la novela inspiró no solo a grandes compositores de música clásica, sino también a autores de música popular. El grupo de hard-rock serbio Hexagram incluyó en su álbum Noche de viento oriental la canción cuya letra reproducimos a continuación:

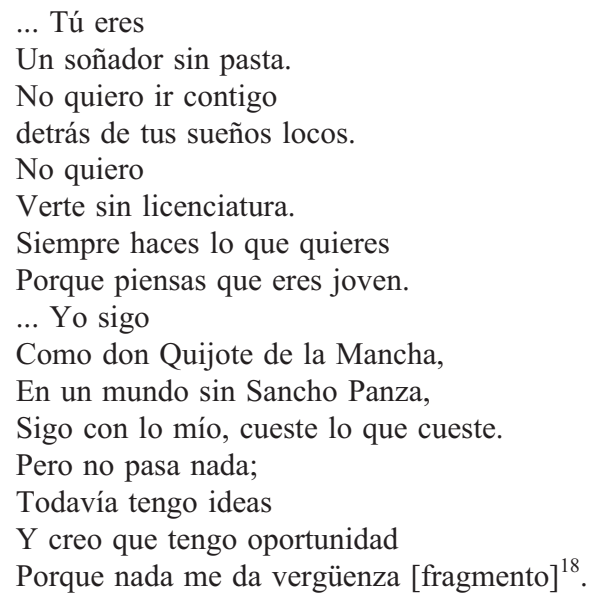

Uno de los mejores guitarristas clásicos españoles, José María Gallardo del Rey, actuó en Zemun, en la Ópera Madlenianum, el 7 de mayo de 2005, e interpretó sus obras compuestas para el ballet Don Quijote. La pianista belgradense Sara Marjanović, que lleva catorce años viviendo y trabajando en Madrid, presentó en septiembre del mismo año un programa musical que incluyó la Serenata a Dulcinea de Ernesto Halffter y Danzas del Ballet Don Quijote de Robert Gerhard.

17. Vladimir TASić, op. cit.

18. «Ti si / Samo sanjar bez love / I s tobom, kroz lude snove, / Neću da idem sad. / Ne želim / Da vidim te bez diplome / Ti uvek radiš po svome / Jer misliš da si još mlad. / [...] A ja još uvek, / K'o Don Kihot od Manče, / U svetu bez Sanča Panse, / Idem glavom kroz zid. / Al' dobro je, / Ipak imam ideju / I mislim da imam / Šanse, / Jer ničeg me nije stid». 


\title{
ESPECTÁCULO CALLEJERO DEL 23 DE ABRIL DE 2005
}

\author{
¿Qué héroe más fantástico es Don Quijote y ¿quién no le \\ amaría, a pesar de las tonterías que hace?! (Božidar Petra- \\ nović, Don Kišot, 1838) $)^{19}$
}

El 23 de abril de 2005 fue el día más espectacular de la celebración. En honor del escritor y de sus protagonistas, el Instituto Cervantes de Belgrado montó un espectáculo en la céntrica calle Knez Mihajlova. Al mediodía en punto, desde el edificio del Instituto hasta el parque Kalemegdan (que domina la desembocadura del Sava en el Danubio), salió un desfile encabezado por Rambo Amadeus, el provocativo músico que arrasa entre los jóvenes belgradenses, ataviado como don Quijote, y acompañado por su percusionista Trut, en traje de Sancho. A sus espaldas brincaban los juglares y músicos del grupo Ioculatores Slovenses, así como los actores del teatro de movimiento Mimart. Enfrente de Kalemegdan les esperaban un caballo y un burro. Rambo se dirigió a los asistentes: «El mayor poder es el saber: por eso, ¡leed, leed y solo leed! Leed libros, periódicos, placas, carteles, correos electrónicos...». El programa continuó con la música de la orquesta juvenil Renaissance y el baile de los Ioculatores. El espectáculo se cerró con la actuación del grupo Los Cosmos, que representó el entremés El juez de los divorcios.

\section{OTROS EVENTOS}

La exposición de ediciones de Don Quijote de los fondos de la Biblioteca de Matica srpska en Novi Sad tuvo lugar del 3 de agosto al 5 de septiembre de 2005. Se expusieron ochenta y seis libros ordenados cronológicamente: trece ediciones en serbio, unas cuantas en húngaro, ruso, español, inglés, albanés, alemán, croata, esloveno y macedonio. Los visitantes también pudieron ver fotografías de los traductores de Don Quijote al serbio y consultar una bibliografía sobre la novela. El catálogo, preparado por las comisarias de la exposición Ksenija Šulović y Olivera Mihajlović, contiene textos sobre Don Quijote de Ortega y Gasset, Borges, Ljiljana Pavlović-Samurović, Jasna Stojanović, Duško Vrtunski, Vladimir Vujić, Vladimir Koljević y Sreten Marić.

Bajo el nombre «La gira de Don Quijote» se esconde una excursión por los campos de Voivodina, mediante la cual tres chicos y una chica serbia celebraron, el 17 de marzo de 2005, el cuatrocientos aniversario de Don Quijote. Salieron de Novi Sad con dirección del molino de Čurug, que fue trasladado desde Hungría en 1842. Este viejo molino no tiene aspas; se le cayeron porque,

19. «Kakav je čudnovati iroj Don Kišot i tko ga ne bi ljubio, kod sviju budalaština što čini?» (Apud J. Stojanović, Servantes u srpskoj književnosti, p. 204). 
cuando empieza a soplar el viento gornjak ${ }^{20}$, uno tiene que estar vigilando el tejado, que da vueltas para tomar la dirección del viento. La ruta les llevó luego a otro molino, pero esta vez un molino-restaurante, cerca de la pequeña ciudad de Bečej, molino que, para la circunstancia, se denominó «Don Quijote».

La celebración del centenario no se limitó a 2005, porque las actividades en torno a Cervantes siguieron organizándose intensamente incluso después de finalizar el año. Junto a nuevas exposiciones, en noviembre de 2006 se organizó un taller teatral por el Centro para las Investigaciones Teatrales de Novi Sad, con el objetivo de imaginar un don Quijote del siglo XXI. El taller fue realizado por tres directoras de guiñol, procedentes de tres países: Serbia (Emilija Mrdaković de Novi Sad), Eslovenia (Jelena Sitar-Cvetko de Ljubljana) y Croacia (Kruna Tarle de Zagreb).

Hoy en día Don Quijote sigue siendo espejo de acontecimientos espirituales, y una vía de toma de conciencia de generaciones que aún se miran en él. Es como si durante sus interminables conversaciones el Caballero de la Triste Figura y su sabio escudero hubiesen anunciado cosas que todavía siguen actuales (Sreten Marić, El loco trágico, 1968)21.

Cervantes y su Quijote llegaron a Serbia a finales del siglo XVIII para alcanzar, a principios del XXI, la publicación de la tercera versión serbia de la novela y un cuarto centenario repleto de eventos. El hidalgo manchego es uno de los personajes literarios preferidos por los lectores serbios, y la obra de Cervantes una fuente inagotable para nuestros escritores, que sacan de ella el hilo con el que tejen la tela de sus propias creaciones. No obstante, esta influencia rebasa los límites de la literatura, inundando otros campos de la creación artística y espiritual, así como la cultura en general y la vida de todos los días.

Sin duda, la obra maestra de Cervantes - como, por lo demás, su pensamiento y su arte de narrar- no cesan de alentar a las nuevas generaciones a descubrir y descifrar de nuevo los mensajes y las ideas que el castellano famoso nos dejó en herencia.

20. Un tipo de viento del norte.

21. «I do danas Don Kihot je ogledalo duhovnih zbivanja i osvešćenja generacija koje su se u njemu ogledale. Kao da su Vitez od Tužnoga Lica i njegov mudri konjušar tokom svojih beskonačnih razgovora nagovestili mnoge i danas aktuelne stvari» (SRETEN MARIĆ, «Tragična luda», M. ŠUKALO, J. StoJANOVIĆ [coords.], op. cit, pp. 52-53). 


\section{BIBLIOGRAFÍA}

\section{Traducciones de obras de Cervantes}

Migel de Servantes, Maštoglavi idalgo Don Kihote od Manče, AleKsandra ManČić (trad.), Beograd, Rad, 2005, 2 vols.

— «Da Vas više niko ne uhvati u neznanju» [fragmento de Don Quijote], AleKsandra MANČIĆ (trad.), Književni list, 2005, 33, p. 10.

\section{Libros sobre Cervantes}

Jasna Stojanović, Servantes u srpskoj književnosti, Beograd, Zavod za udžbenike i nastavna sredstva, 2005, $334 \mathrm{pp}$.

Jasna Stojanović (coord.), Don Kihot u srpskoj kulturi, Beograd, 19-24 april 2005, Beograd, Filološki fakultet, Institut Servantes, 2006, 119 pp.

Mladen ŠuKalo i Jasna Stojanović (coords.), Don Kihot 1605-2005, Krajina, 2005, 327 pp.

AleKSANDRA MANČIĆ, Vetrenjače na jezik, Beograd, Rad, 2005, 148 pp.

\section{Artículos sobre Cervantes}

LJILJANA PAVlović-SAmuRović, «Servantesov 'Don Kihot' danas - proučavanje i vrednovanje», Letopis Matice srpske, 476, 2005, 6, pp. 1068-1088.

- «Društvene i kulturno-književne prilike u Španiji u vreme nastanka Don Kihota», M. Šukalo i J. Stojanović (coords.), Don Kihot 1605-2005, Krajina, 2005, 15, pp. 24-45.

IsIDORA SEKULIĆ, «Beleške uz čitanje: Servantes», ibíd., pp. 46-51.

SRETEN MARIĆ, «Tragična luda», ibíd., pp. 52-83.

Svetozar Koljević, «Igra slike i iskustva u Don Kihotu», ibíd., pp. 84-108.

NiKola MilošEvić, «Don Kihot i nihilizam», ibíd., pp. 109-140.

Mladen ŠUKALO, «Nečujno središte poretka riječi», ibíd., pp. 141-197.

JaSna Stojanović, «Servantes na Helgolandu. Odjeci Don Kihota u delima Radomira Smiljanića», ibíd., pp. 198-221.

— «Servantesov 'Don Kihot' i društveni romani Jakova Ignjatovića», Letopis Matice srpske, 476, 2005, 6, pp. 1089-1106.

— «Servantesove Uzorne novele u prevodu Hajima Alkalaja», Philologia, 2005, 3, pp. 219-225.

— «Servantes u srpskoj književnosti», Politika, 28.IV.2005-8.V.2005.

— «Don Kihot u srpskoj kulturi», JAT New Review, 2005, sept., pp. 36-40.

NovicA Milić, «Don Kihot i književnost», Književni list, 2005, 32, pp. 1, 12-13.

ALEKSANDRA MANČIĆ, «Subotnji post i prezime mančanskih supruga: jedno marginalno pitanje u prevođenju Servantesovog Don Kihota», ibíd., 2005, 39, pp. 1, 6.

Zoran KonstantinOviĆ, «Srbin kao Don Kihot», NIN, 2005, 2868, pp. 52-53.

Branislava JeVtoviĆ, «Četiri veka Don Kihota, kralja Lira i Otela», Književne novine, LVII, 2005, 1124, p. 6.

Radoslav Vojvodić, «Don Kihot protiv Hristosa - Objašnjenje uz pesmu 'Don Kihot u Pionirskom parku», NIN, 2005, 2862, pp. 48-49. 
Vladimir TASić, «O Besmrtnosti - lik Don Kihota u svetskoj književnosti», Vreme, 28.IV.2005, p. 747.

Vladimir PIŠTalo, «Svačiji rodjak iz Manče», Vreme, 3.III.2005, p. 739.

Milka KnežEvić-IvašKović, «Hamlet i Don Kihot», Politika (Kultura, umetnost, nauka), dic. 2005 , p. 11.

ŽArko TrebJeŠAnIN, «Donkihotizam u Srba», Glas javnosti, 30.IV.2005.

AleKSANDRA MANČÍc, «Don Kihote medju Srbima», Politika, 2.VIII.2005.

OBRad Stanojević, «Don Kihot i paraćinske koprive (jeretički pogled na Servantesa»), Hereticus, 2005, 2, pp. 115-126.

BoJAn Jovanović, «O umnoj ludosti», Zlatna greda, 2005, p. 27.

Zoran Avramović, «Kultura mišljenja i Don Kihot», Koraci, 2005, 9-10, pp. 153-166.

\section{Traducciones de libros y artículos sobre Cervantes y su obra}

Andres Trapijeljo, Po smrti Don Kihota, Jelena PlavšIć (trad.), Beograd, ASNS, 2005, $290 \mathrm{pp}$.

- Životi Migela de Servantesa, Jelena PlavŠlć (trad.), Beograd, ASNS, 2005, 215 pp.

Hose Martines Ruis, Asorin, Stazama Don Kihota, Biljana Bukvić (trad.), Beograd, Utopija, 2005, $118 \mathrm{pp}$.

Horhe Luis Borhes, «Pjer Menar, pisac Kihota» (BožIDAR Marković [trad.]), M. ŠUKalo i J. Stojanović (coords.), Don Kihot 1605-2005, pp. 13-22.

FranC KAFKA, «Istina o Sanču Pansi», BRANImIR ŽIVOJINOviĆ (trad.), ibíd., p. 23.

MARTA Rober, «Epska istina», SANJA Dokić (trad.), ibíd., pp. 222-248.

HaUARD Mensing, «Metafikcijska dijalektika u Don Kihotu», ANDJElKa NićIForoVIĆ-GRANDIĆ (trad.), ibíd., pp. 249-269.

DžON Dž. ALEN, «Pastoralni stil i žanr u Don Kihotu», trad. ANDJELKA NićIFOROVIĆ-GRANDIĆ, ibíd., pp. 270-274.

Ivon JeHENSON, «Pastoralna epizoda u Servantesovom Don Kihotu: Marsela još jednom», Maja ŠUKalo (trad.), ibíd., pp. 275-297.

Mario Vargas Ljosa, «Roman za XXI vek», Jovana Zelić (trad.), ibíd., pp. 298-309.

Margit FrenK, «Umetnost, pisanje, čitanje», Jovana Zelić (trad.), ibíd., pp. 318-325.

KArlos Fuentes, «Pohvala neizvesnosti», Jovana Zelić (trad.), ibíd., pp. 310-317.

— «Pohvala romana», NIN i Le monde diplomatique, dic. 2005, pp. 24-25.

HorHe LuIS BORHES, «Skrivene čarolije Don Kihota», Politika (Kultura, umetnost, nauka), 2005, 58, pp. 3-4.

FJodor Minailovič Dostojevski, «Laž se lažju spasava», ibíd., p. 5.

Recibido: 18-9-2006

Aceptado: 4-4-2008 


\title{
Resumen
}

En este trabajo, realizado en la Cátedra de Estudios Ibéricos de la Facultad de Filología de Belgrado, se reúnen los datos sobre la recepción de la obra cervantina en Serbia durante 2005. La presencia del autor y la difusión de su obra han sido analizadas a través de varias actividades artísticas, científicas y culturales organizadas a lo largo del año. Atención especial han merecido las nuevas traducciones de títulos cervantinos y las nuevas críticas. Asimismo, se ha elaborado una bibliografía completa del material editado con motivo de la conmemoración.

Palabras clave: Cervantes. 400 aniversario de Don Quijote. Recepción. Serbia, Actividades culturales.

Title: Cervantes' year in Serbia

\begin{abstract}
This work, realized at the Cathedra of Iberian Studies of the Faculty of Philology, University of Belgrade, compiles the data on the reception of Cervantes' work in Serbia during 2005. The author's presence and the diffusion of his texts were analyzed through various artistic, scientific and cultural activities organized during the year. Special attention was paid to new translations of the Cervantine titles and recent critics. On the occasion of the commemoration, a complete bibliography of the edited material was elaborated as well.
\end{abstract}

Key words: Cervantes. 400th anniversary of the first edition of DQ. Reception. Serbia. Cultural activities. 